\title{
Using Health QR Code to Fight Against COVID-19: Chinese Government's New Way of Collaborative Governance With Enterprises
}

\author{
Ting Lei ${ }^{1,2, *}$ Jiaxin Deng ${ }^{1}$ Yubo Xie ${ }^{2}$ Yibo Tian ${ }^{3}$
}

\author{
${ }^{1}$ School of Public Affairs and Administration, University of Electronic Science and Technology of China, Chengdu, \\ Sichuan 611731, China \\ ${ }^{2}$ School of Computer and Communication Sciences, EPFL, Lausanne 1025, Switzerland \\ ${ }^{3}$ College of Petroleum Engineering, China University of Petroleum, Beijing 102249, China \\ *Corresponding author. Email: leiting_uestc@163.com
}

\begin{abstract}
While still raging globally, coronavirus disease 2019 (COVID-19) has had a severe impact on people's lives in the world. For the first time, the Chinese government cooperated with enterprises and introduced health $Q R$ code, to ensure the safety of its citizens. This is a new way of collaborative governance with enterprises, offering much experience for containing the spread of the COVID-19 epidemic. This article will first explain what health QR code is, and then, from the perspective of collaborative governance, analyze the main modes and characteristics of the health $Q R$ code introduced on social platforms such as Alipay and WeChat. The cooperative operation of health QR codes by the government and enterprises is an innovative and important attempt, not only for enterprises to provide accurate social services for the government, but also for the government to mine large-scale data with the help of enterprises. At the moment, health QR codes have been widely adopted while work resumption is taking place in China, providing beneficial reference for the global fight against the COVID-19 epidemic.
\end{abstract}

Keywords: collaborative governance, COVID-19, health QR code

\section{INTRODUCTION}

The COVID-19 epidemic has received much attention worldwide. In December 2019, several cases of acute respiratory infection caused by novel coronavirus (COVID-19) were discovered in Wuhan, Hubei Province, China [1]. Subsequently, COVID-19 began to spread throughout China, and 31 provincial governments in the Mainland of China activated firstlevel public health emergency response, in hope of bringing the epidemic under control. On January 30, 2020, the World Health Organization (WHO) declared the outbreak of novel coronavirus a Public Health Emergency of International Concern (PHEIC)[2]. As of April 25, 2020, a total of 2,775,256 people in 211 countries and regions had been infected with the COVID-19 virus, which had caused 196,864 deaths [3]. At this time, the COVID-19 epidemic in China has been brought under control. Most provinces have resumed work and study, and entertainment services are reopening. Emerging information technology, ubiquitous in business, public health and daily life, have become an important technical means for governments to reform their governance. The use of health codes based on information technology in the COVID-19 outbreak has played a vital role in controlling the epidemic and ensuring citizens' travel safety.

On February 11, 2020, the Hangzhou Municipal Government and Alipay formally launched the "Hangzhou Health Code" as a digital empowerment method to strengthen epidemic prevention and control, providing health monitoring services for citizens [4] The health code is based on real network location data combined with citizen's online self-declaration of travel history, which is reviewed and verified by the platform, to generate a QR code used as an electronic voucher for citizens to enter and exit in the respective regions. On February 29, 2020, the Chinese government announced the "Anti-Epidemic Health Information Code" on the national government service platform, which can be easily generated on WeChat or the government's official website [5]. The cooperation between governments and enterprises can effectively monitor the travel history of citizens and thus control the epidemic situation. As of now, the Chinese government has been using health QR code to fight against COVID-19: Chinese government's new way of collaborative governance with established an inter-provincial mutual 
recognition mechanism on health codes and has carried out technology transfer and data aggregation across various provinces (regions and cities). Relying on the national integrated government platform as well as Alipay and WeChat, various provinces (regions and cities) are now sharing epidemic controlling information and mutually recognize the others' health codes. Most cities in China have achieved "one code access". With the rapid changes in the social environment on which public management activities depend, digitalization has become the theme of the era [6]. The government's dependence on other departments in public management has also gradually increased. There is a need to establish a wide range of cooperative relationships among governments, enterprises, and nonprofit organizations, and collaborative governance is becoming the new trend [7]. The rise of collaborative governance stems directly from the need to deal with increasingly complicated public policy issues. The theory of collaborative governance originates from classical liberalism and republicanism, and takes resource dependence theory, transaction cost economics and organizational ecology as its theoretical basis [8], [9], [10], [11]. Collaborative governance is a governance concept different from traditional government management based on bureaucracy. Collaboration is a higher form of inter-organizational relationship than cooperation. It emphasizes the participation of multiple subjects with a common goal and becomes a true decision maker[7], [12], [13]. Collaborative subjects must act together and have equal status, but do not exclude the existence of actual leaders. Based on the concept of collaborative governance, Robert Agranoff believes that collaboration is multi-level, which exists not only vertically between government departments at different levels but also horizontally between government departments, NGOs, and state-owned and private enterprises[14]. The concept of collaborative governance is in line with the reality that China's social governance is currently moving from government acting as the sole subject to multi-governance with the government playing a leading role [15]. Relying on massive users and technological advantages, Alipay and WeChat developed and operated the health codes according to the "Reference Architecture and Technology Guide of Anti-Epidemic Health Code" issued by the Chinese government and the society's needs of supervising epidemic prevention and control. On the other hand, the Chinese government launched the inter-provincial mutual recognition mechanism on health codes, and realized the sharing of epidemic prevention information, technology transfer, and data aggregation among provinces (regions and cities), relying on the national integrated government affair platform. The health code jointly operated by the Chinese government and Alipay/WeChat is a successful new governance method attempted by the government and enterprises for prevention and control of epidemics in the context of the digital era [16], [17]. Health QR code will provide valuable experience reference for current global prevention and control of COVID-19.

\section{HEALTH QR CODE}

The world's first health QR code is the "Hangzhou Health Code" officially launched and operated by the Hangzhou Municipal Government and Alipay on February 11, 20220. The health code is based on the real network location data combined with citizen's selfdeclaration of travel history on the government's official website, Alipay or WeChat, after linking their resident ID cards. This QR code can be used as an electronic voucher for citizens to enter and exit in their respective areas. Health codes generally adopt three color patterns, namely "green code", "red code", and "yellow code":

- The green health QR code indicates that the citizen can enter the city where this code is operated.

- The red health QR code indicates that the citizen cannot immediately enter the city and needs to be quarantined for 14 days, either at home or collectively. After 14 days of normal health monitoring, the health QR code will turn green.

- The yellow health QR code indicates that the citizen can enter the city, but needs to be quarantined for 7 days, either at home or collectively.

After continuous health declaration, if at the end of the isolation period the citizen's health is normal, the code will change to green [18]. The health QR code has usage scenarios such as civic transportation, community services, enterprise production resumption, school resumption, supermarket shopping, medicine purchase, etc. It is an important means of assistance for enterprises, communities and schools to contain the epidemic. In the prevention and control of the epidemic and resumption of work and study, the health QR code can efficiently help managing crowds in train stations, subways, shopping malls and other places, avoiding excessive contact and gathering.

\section{THE DEVELOPMENT HISTORY OF GOVERNMENT-ENTERPRISE COOPERATION IN OPERATING HEALTH QR CODES}

\section{A. Early stage}

This stage is mainly a one-way collaboration attempt between Alipay and the municipal government. On February 11, 2020, the Hangzhou Municipal Government in Zhejiang Province introduced the health code on the Alipay platform for the first time in the 
city, and adopted three color patterns (green, red, and yellow) to manage the people who intend to enter Hangzhou [18].

\section{B. Middle stage}

This stage is mainly a horizontal collaboration attempt between Alipay and local governments under the guidance of the Chinese central government. On February 15, the E-Government Office of the General Office of the State Council instructed Alipay and Alibaba Cloud to accelerate the development of a national integrated government service platform for epidemic prevention and control health codes. On February 28, 2020, Alipay announced that the health code has covered more than 200 cities in China, and achieved full coverage in Zhejiang, Sichuan, Hainan, Chongqing, Shanghai, Yunnan, Shanxi, Hubei and other provinces and cities. As enterprises resume production, the coverage is expanding to other cities, and people in Hangzhou and Wenzhou can now use the code to see doctors and buy medicines [19].

\section{Final stage}

At this stage, the central government, Alipay, and WeChat attempted a unified vertical collaboration across the country. On February 29, 2020, the Chinese government launched the "Anti-Epidemic Health Information Code" on the national government service platform[5]. Citizens can use the "National Government Service Platform" WeChat applet, the "Anti-Epidemic Health Code" in WeChat City Services and Alipay Health Code to apply for a citizen's personal epidemic prevention code after completing real-name authentication and truthfully reporting personal health information. In the press conference of the Joint Prevention and Control Mechanism of the State Council of China, held in the afternoon of March 20, 2020, Mao Qunan, director of the Planning Department of the National Health Commission, said that at present, 98\% of the county-areas in China now have low risk of COVID-19 epidemic. According to the data format standards and content requirements, each province is accelerating the process of integrating the local epidemic information catalogues into the national integrated platform, and the health codes in most areas of the country can be universally recognized.

\section{THE MAIN MODES OF GOVERNMENT- ENTERPRISE COOPERATIVE OPERATION OF HEALTH}

The government is the executor of relevant standards and policies, and the enterprises are the actual providers of health code services [12]. The Chinese government issued the "Reference Architecture and Technology Guide of Anti-Epidemic Health Code" on March 5, 2020, which articulates the technical requirements for the health code developers and regulations regarding the personnel management, authorization management, and collection point management in places where health code is used. Alipay and WeChat then provide health QR code services based on relevant government policies and specific needs. Citizens can use the "National Government Service Platform" WeChat applet, the "Anti-Epidemic Health Code" in WeChat City Services and Alipay Health Code to apply for a citizen's personal epidemic prevention code after completing real-name authentication and truthfully reporting personal health information. Subsequently, the "National Integrated Government Service Platform Anti-Epidemic Health Information Code Interface Standard" was published to gradually connect the anti-epidemic health information code on the national government service platform with the health codes in Guangdong, Shanghai, and etc. Based on the data and information code services shared by the national government service platform, all localities are responsible for providing local health QR code related management and services according to the needs of epidemic prevention and control, and gradually realize mutual recognition on health information codes in various regions. At the same time, China's integrated government service platform provides three ways to achieve mutual recognition and sharing of health QR codes across regions. The first way is to add the functionalities of mutual recognition into the local health QR code by leveraging the shared anti-epidemic health data, without changing the existing specifications of the local health code. The second way requires the integration and docking of the health $\mathrm{QR}$ codes in various regions with the "Anti-Epidemic Information Code" on the national integrated government service platform, which serves as an intermediary, thus realizing the mutual recognition of the health codes across the country. For areas without local health codes yet, the third way is to directly use the "Anti-Epidemic Information Code" on the national integrated government service platform and integrate the anti-epidemic related information of the region itself, so as to achieve the mutual recognition with other regions.

\section{THE MAIN CHARACTERISTICS OF GOVERNMENT-ENTERPRISE COOPERATIVE OPERATION OF HEALTH QR CODE}

Relying on the advantages of technology and users, enterprises are able to provide sophisticated and specialized social service management for the government [17]. Alipay is the largest third-party payment platform in China, with 1.2 billion Chinese users, providing multiple functions such as electronic payment, social security payment, city services and financial services. 
WeChat is China's number one social software, with its number of Chinese users exceeding 1.1 billion, providing multiple functions such as voice and video chat, electronic payment, city services and travel services. Alipay and WeChat are inevitable software for Chinese citizens in their daily lives. Behind them are Alibaba and Tencent, two of the most powerful Chinese information technology companies. Using its strong technical advantages and the massive number of users, Alipay or WeChat can accurately provide individual users with customized travel services during the epidemic, and also provide important technical means for the government to carry out social management for epidemic prevention and control, which can efficiently monitor the movement of citizens. The "National Government Service Platform" is the first national government service applet, technically supported by Tencent Cloud. At the moment, there are nearly 10 million registered users. As of March 5, 2020, the cumulative number of code showing exceeded 1 billion, covering more than 800 million people, and the cumulative number of visits was 4.3 billion.

This is also the government's first attempt to open large-scale government information databases to enterprises [14]. While providing the health QR code services, Alipay and WeChat directly rely on the unified identity authentication system and the unified electronic license system of the national government service platform, taking advantages of the collected data on health, civil aviation, railway, etc. After the real-name authentication of the health code services, the public can also check the details of personal antiepidemic health information with just one click, for example whether he/she is a confirmed or suspected patient of COVID-19, and whether he/she is a person in close contact with other confirmed cases. This is the first time the Chinese government opened its largescale data to enterprises, an important practice for the government to transform data resources into data capital, and an effective exploration to promote the government's digital reformation, offering experiences for governments providing more diverse public services in the context of digital era.

\section{CONCLUSION}

Collaborative governance in the context of China attaches importance to the participation of multiple subjects in the management of social public affairs and truly plays a role in decision-making [20]. It also supports the government's ability to assume a defector leadership role in the process of collaborative governance. In the current process of Chinese society's transition from a omnipotent government model to pluralism, social organizations, state-owned and private enterprises, and individual citizens are all subjects of social governance, but the role of the government is still irreplaceable, and collaborative governance is more likely to bring good governance effects[21]. The "Health QR Code", co-developed and operated by Alipay/WeChat and the Chinese government, not only guarantees the travel safety of citizens, but also provides support for businesses' work resumption and citizens' consumption activities. The health QR code details the personal profiles of the citizens, the location of family residence, and the physical health status at home, including temperature status. Only after scanning the health QR code and validated by the employers can the employees enter the offices. Enterprises can also scan health codes for online record registration. After applying for health codes, citizens are able to realize "one login, multiple accesses", which reduces contact, facilitates the masses, and promotes consumption. The health QR code promoted by China during the epidemic is of great significance to the prevention and control of the epidemic. Just like the credit status of a person, the health QR code attaches more and more value to the health status of a person. Especially during a public health emergency, it constructs a national citizen health information supervision network, which will have more and more value of application and digital empowerment. In response to the severe epidemic in China, the health QR code has an obvious positive effect [21]. It plays a vital role in urban governance, population mobility, and dynamic management of the health status of the entire population. The population is classified and managed accordingly — those holding "green codes" can resume work and return to school as normal, while those holding yellow and red codes are required to be quarantined, which on one hand is conducive to precision medical treatment and on the other hand benefits production resumption in order. In the future, it is necessary to pay attention to the role of "health code" and other scientific and technological means in national emergency protection. In fact, it can form a national health brain in a certain sense, which can be used as the basis for national health research and become an important national epidemic analysis and prevention tool. Simultaneously, as a digital means of urban governance and national emergency security capabilities, it can greatly save the cost of urban governance in the economic sense, improve the efficiency of national governance, stabilize social order, and enhance citizens' sense of health and security [15], [22], [23]. The use of health QR codes during the epidemic in China is of great significance in the digital era. It not only provides digital means for the prevention and control of epidemics for governments around the world, but also is an important and innovative attempt for collaborative governance between governments and enterprises. 


\section{References}

[1] Kang, D., et al., Spatial epidemic dynamics of the COVID-19 outbreak in China. International Journal of Infectious Diseases, 2020. 94: p. 96-102.

[2] Arshad Ali, S., et al., The outbreak of Coronavirus Disease 2019 (COVID-19) - An emergingglobal health threat. Journal of Infection and Public Health, 2020. 13(4): p. 644-646.

[3] COVID-19 virus infection data. 2020. https://mp.weixin.qq.com/s/V3ZQ2SFAy2NlicKk4zXpag

[4] Hangzhou Municipal Government announced the official launch of the health QR code.

[5] China Epidemic Prevention Information Code. http://www.cdwh.gov.cn/wuhou/c106081/202003/19/content_b 74c93d30b6945ada7aa34f3e57a9561.shtml

[6] Dunleavy, P., New Public Management Is Dead-Long Live Digital-Era Governance. Journal of Public Administration Research \& Theory, 2005(3): p. 3.

[7] Taehyon, C. and R.P. J, Contributors and Free-Riders in Collaborative Governance: A Computational Exploration of Social Motivation and Its Effects. Journal of Public Administration Research and Theory, 2018(3): p. 3.

[8] Johnston, E.W., et al., Managing the Inclusion Process in Collaborative Governance. Journal of Public Administration Research \& Theory, 2010(4): p. 4.

[9] Emerson, K., T. Nabatchi and S. Balogh, An Integrated Framework for Collaborative Governance. Journal of Public Administration Research and Theory, 2012. 22: p. 1.

[10] Agranoff, R. and M. McGuire, Collaborative public management: New strategies for local governments. 2003.

[11] Gash, C.A.A.A., Collaborative Governance in Theory and Practice. Journal of Public Administration Research \& Theory, 2008. 18(4): p. p.543-571

[12] Donahue, J., R. Zeckhauser and S. Breyer, Collaborative governance: Private roles for public goals in turbulent times. Collaborative Governance: Private Roles for Public Goals in Turbulent Times, 2011: p. 1-305.

[13] Hambleton, R., The New Civic Leadership: Place and the cocreation of public innovation. Public Money \& Management, 2019: p. 1-9.

[14] Agranoff, R. and M. Mcguire, Collaborative Public Management: New Strategies for Local Governments. 2004: Georgetown University Press.

[15] Li, F., J. Chen and Y. Su, Managing the university-industry collaborative innovation in China: The case of Zhejiang NHU Company. Journal of Organizational Change Management, 2018. 31: p.00-00.

[16] Pereira, G., et al., Increasing collaboration and participation in smart city governance: a cross-case analysis of smart city initiatives. Information Technology for Development, 2017.

[17] Bodin, Ö., A. Sandström and B. Crona, Collaborative Networks for Effective Ecosystem-Based Management: A Set of Working Hypotheses. Policy Studies Journal, 2016: p. n/a-n/a.

[18] Hangzhou Health and Health Commission announced the official use of health QR code.

[19] Alipay Health Code covers more than 200 cities in China. https://www.sohu.com/a/3760076 34_120191893

[20] O'Leary, R. and L. Amsler, Collaborative Public Management. International Public ManagementJournal, 2007. 10: p. 1-10.

[21] Sørensen, E. and J. Torfing, Making Governance Networks Effective and Democratic Through Metagovernance. Public Administration, 2009. 87: p. 234 - 258.

[22] Bekker, M., et al., Comparative institutional analysis for public health: governing voluntary collaborative agreements for public health in England and the Netherlands. European journal of public health, 2018. 28.

[23] Cooper-McCann, P., A Review of "Collaborative Governance for Urban Revitalization: Lessons From Empowerment Zones". Journal of the American Planning Association, 2014. 80: p. 279 279 . 